\title{
Electrochemical Analysis of the Corrosion Behavior of Drill Pipe Steel under Oil/Water Emulsion Condition
}

\author{
Yisheng $H u^{1,2^{*}}$, Yu Peng ${ }^{1}$, Jinzhou Zhao ${ }^{1}$, Ping Guo ${ }^{1}$, Siping Long ${ }^{3}$ \\ ${ }^{1}$ State Key Laboratory of Oil and Gas Reservoir Geology and Exploitation, Southwest Petroleum \\ University, Chengdu, 610500, China \\ ${ }^{2}$ Department of Earth Science and Engineering, Imperial College London, London, SW7 2AZ, UK \\ ${ }^{3}$ Sichuan Geophysical Company, CNPC, Chengdu, 610213, China \\ *E-mail: huyisheng008@yahoo.com
}

doi: $10.20964 / 2017.09 .10$

Received: 21 May 2017 / Accepted: 19 June 2017 / Published: 13 August 2017

This work proposed a rotating disk electrode strategy to study the electrochemical corrosion performance of API-X100 pipeline steel immersed in a simulated oil/water emulsion under controlled electrochemical and hydrodynamic conditions. The mass-transfer of oxygen was found to be crucial to the cathodic process of steel in solution both before and after the addition of oil. Electrode rotation sped up the cathodic reduction by accelerating oxygen diffusion. In the solution, after the addition of oil, there was an increment in the limiting diffusive current density (LDCD), which resulted from the enhanced solubility of oxygen in the oil/water emulsion. The anodic current density decrease caused by the electrode rotating speed (ERS) increment resulted from the accelerated oxygen diffusion and reduction along with the enhancement in the oxidation of the steel. With the addition of oil, the anodic dissolution of steel decreased. This phenomenon was ascribed to the fact that a layer of an oily phase formed on the surface of the steel and the reaction activation energy increased. Upon the addition of oil, a variation of the corrosion reaction mechanism was observed, indicating the activation-controlled feature of the interfacial reaction instead of the mass-transfer controlled property.

Keywords: Corrosion behavior; Electrochemical analysis; Drill pipe steel; Oil/water emulsion

\section{FULL TEXT}

(C) 2017 The Authors. Published by ESG (www.electrochemsci.org). This article is an open access article distributed under the terms and conditions of the Creative Commons Attribution license (http://creativecommons.org/licenses/by/4.0/). 